Article

\title{
Alginate-Poly(ethylene glycol) Hybrid Microspheres for Primary Cell Microencapsulation
}

\author{
Redouan Mahou $^{1{ }^{\prime} *}$, Raphael P. H. Meier ${ }^{2}$, Léo H. Bühler ${ }^{2}$ and Christine Wandrey ${ }^{1, *}$ \\ 1 Institut d'Ingénierie Biologique et Institut des Sciences et Ingénierie Chimiques, Ecole Polytechnique \\ Fédérale de Lausanne, EPFL-SV-IBI-LMRP, Station 15, Lausanne CH-1015, Switzerland; \\ 2 \\ Surgical Research Unit, University of Geneva, CMU-1, Geneva CH-1211, Switzerland; \\ E-Mails: raphael.meier@ hcuge.ch (R.P.H.M); leo.buhler@ hcuge.ch (L.H.B.) \\ * Authors to whom correspondence should be addressed; E-Mails: redouan.mahou@epfl.ch (R.M.); \\ christine.wandrey@epfl.ch (C.W.); Tel.: +41-21-693-9661 (C.W.); Fax: +41-21-693-9685 (C.W.).
}

Received: 11 November 2013; in revised form: 17 December 2013 / Accepted: 2 January 2014 /

Published: 9 January 2014

\begin{abstract}
The progress of medical therapies, which rely on the transplantation of microencapsulated living cells, depends on the quality of the encapsulating material. Such material has to be biocompatible, and the microencapsulation process must be simple and not harm the cells. Alginate-poly(ethylene glycol) hybrid microspheres (alg-PEG-M) were produced by combining ionotropic gelation of sodium alginate (Na-alg) using calcium ions with covalent crosslinking of vinyl sulfone-terminated multi-arm poly(ethylene glycol) (PEG-VS). In a one-step microsphere formation process, fast ionotropic gelation yields spherical calcium alginate gel beads, which serve as a matrix for simultaneously but slowly occurring covalent cross-linking of the PEG-VS molecules. The feasibility of cell microencapsulation was studied using primary human foreskin fibroblasts (EDX cells) as a model. The use of cell culture media as polymer solvent, gelation bath, and storage medium did not negatively affect the alg-PEG-M properties. Microencapsulated EDX cells maintained their viability and proliferated. This study demonstrates the feasibility of primary cell microencapsulation within the novel microsphere type alg-PEG-M, serves as reference for future therapy development, and confirms the suitability of EDX cells as control model.
\end{abstract}

Keywords: alginate; biocompatibility; cell encapsulation; cell transplantation; hydrogel; microencapsulation; poly(ethylene glycol) 


\section{Introduction}

Microencapsulation of living cells in spherical hydrogel beads or capsules has been intensely studied for more than three decades. There are many clinical trials going on. Despite enormous accumulation of knowledge documented in abundant original papers, reviews and monographs, which confirm the continuous progress in the field, cell microencapsulation has not yet been translated into any established therapy. While allotransplantation of cells can be performed in combination with immunosuppression, there is consensus that cell xenotransplantation will need immunoprotection of the cells by suitable semi-permeable materials produced by standardized technologies. Both materials and technology have to be well adapted to each specific cell type. Currently, relying on existing knowledge together with research and development on the one hand and focus on the improvement of existing approaches on the other hand, researchers are looking for novel strategies.

Hydrogels composed of either covalently or electrostatically crosslinked biocompatible macromolecules mimic, to a certain extent, the natural environment of cells. The high water content renders hydrogels attractive for cell encapsulation/immobilization intended for subsequent transplantation [1-3].

Alginate-based hydrogels are the most frequently reported materials for cell microencapsulation. Although other natural and synthetic polymers are under investigation, hardly any others have attracted the same attention as the calcium alginate (Ca-alg) or the alginate-poly(L-lysine)-alginate (APA) microcapsule [4]. Despite some known physical limitations, there is no doubt about the advantageous properties of Na-alg and its biological acceptance upon ionotropic gelation with divalent cations. The latter was recently confirmed using a human whole blood model to evaluate the inflammatory properties of several microbeads and microcapsules [5,6]. As evident from recent publications, on the one hand research continues with simple calcium and barium alginate microbeads [7-13], while on the other hand poly(L-lysine) has been replaced by poly(L-ornithine) [14] or chitosan [15-18], or alginate has been combined with other compounds such as carrageenan [19] or synthetic methacrylate-based polymers [20-22]. However, using Na-alg in combination with polycations, the chance of success in terms of biocompatibility is uncertain [23]. Alternatively to Na-alg, agarose [24], sodium cellulose sulfate [25] or poly(ethylene glycol) (PEG) and derivatives of these have been used [26,27]. Further, the modification of the alginate backbone with biomolecules [28] as well as alginate-PEG microspheres obtained by crosslinking via Staudinger ligation have been addressed [29].

Taking into account the advantages of both alginate- and PEG-based hydrogels, we have proposed a novel type of hydrogel microsphere. The combination in a one-step process of the electrostatic interaction of calcium ions with $\mathrm{Na}-\mathrm{alg}$ and the chemical crosslinking reaction of vinyl sulfone-terminated multi-arm PEG (PEG-VS) yielded alginate-PEG hybrid hydrogel microspheres (alg-PEG-M) with well-controllable physical properties [30]. The physical properties of the alg-PEG-M, which are tunable in a wide range of interesting biomedical applications [31], have motivated us to study the microsphere formation in biologically relevant media and to investigate the feasibility of cell microencapsulation in alg-PEG-M.

This paper reports and discusses cell microencapsulation of primary human foreskin fibroblasts (EDX cells) as a model. The study was designed to answer primarily the following questions: Is the microsphere formation influenced when it is performed in cell culture medium? How does the PEG concentration influence the stability and durability of alg-PEG-M? Is cell microencapsulation feasible 
in this novel two-component hydrogel prepared in one step without any further coating or reinforcement? Do primary cells maintain their viability for a longer period upon microencapsulation in alg-PEG-M? This is the first study to address these questions for alg-PEG-M.

\section{Results and Discussion}

\subsection{Formation of Alg-PEG-M in Cell Culture Medium}

Alg-PEG-M were prepared in one step by extruding the polymer solution containing PEG-8-20 (Scheme 1) and Na-alg into the gelation bath containing $\mathrm{CaCl}_{2}$ and the crosslinker. Physiological conditions were applied as described in detail in paragraph 3.4 (DMEM, $\mathrm{pH}=7.4, T=37{ }^{\circ} \mathrm{C}$, osmolality $\approx 300 \mathrm{mOsm} / \mathrm{kg}$ ). The microsphere diameter could be tuned by varying process conditions such as airflow, extrusion rate, and the syringe needle diameter. As a typical example, using an inner needle diameter of $400 \mu \mathrm{m}$, microspheres with an average diameter of $550 \mu \mathrm{m}$ and less than $5 \%$ relative standard deviation of the diameter were obtained (Figure 1).

Scheme 1. Chemical structures of 8-arm poly(ethylene glycol) (8-arm PEG-OH) and vinyl sulfone-terminated 8-arm PEG (PEG-8-20) obtained after modification of PEG-OH with a molar mass of $20 \mathrm{~kg} / \mathrm{mol}$.

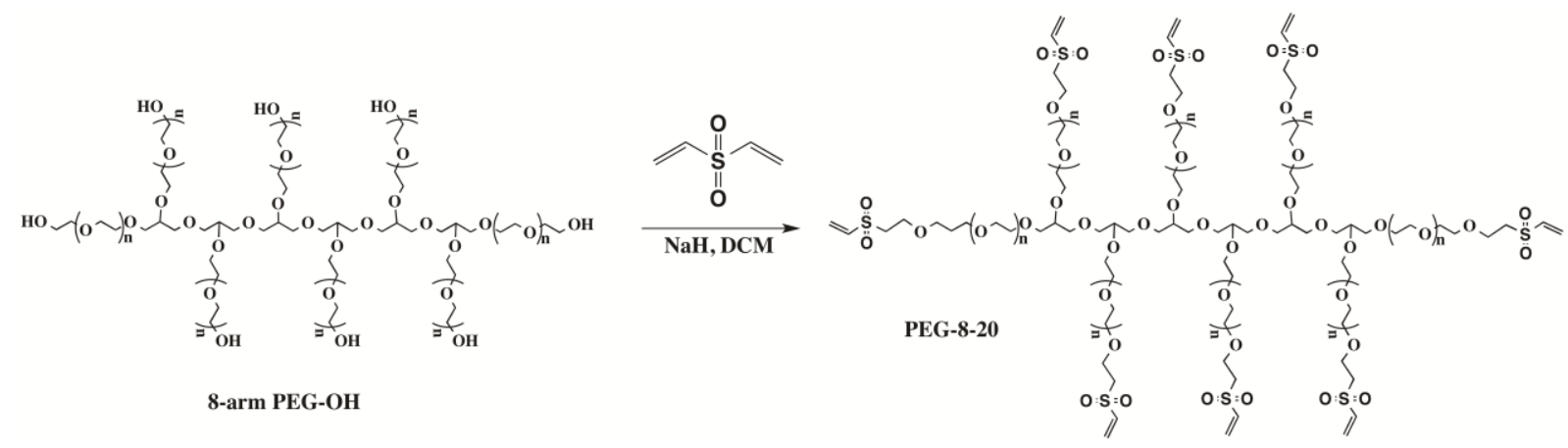

Figure 1. Alginate-poly(ethylene glycol) hybrid microspheres (alg-PEG-M) with an average diameter of $550 \mu \mathrm{m} \pm 5 \%$ SD. Scale bar: $400 \mu \mathrm{m}$.

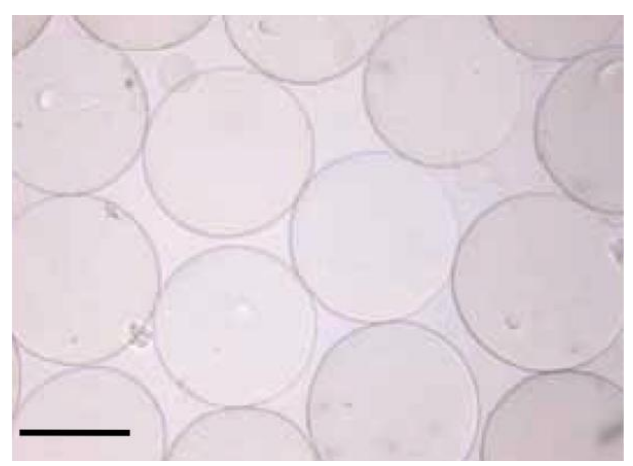

The efficiency of PEG crosslinking for the here used protocol was confirmed after liquefaction of the Ca-alg hydrogel by sodium citrate, yielding stable PEG hydrogel beads above a PEG-VS concentration of $5 \%(w / v)$. Figure 2 shows stable microspheres for pure Ca-alginate beads and PEG-containing microspheres before liquefaction. Complete dissolution was observed for $1.25 \%(w / v)$ 
PEG-VS upon liquefaction. Figure 2 further shows that the microsphere diameter increases with increasing PEG-VS concentration when using the same encapsulation settings for all batches. Consequently, for a targeted microsphere size, the airflow and extrusion rate have to be adapted to the viscosity of the polymer solution. For all experiments and tests performed in this study, liquefaction was omitted in order to keep the microsphere production process simple. However, liquefaction remains an option for further adaptation to specific cell microencapsulation applications.

Figure 2. Microsphere preparations with different concentrations of vinyl sulfone-terminated multi-arm poly(ethylene glycol) (PEG-VS) in $1.5 \%(w / v)$ sodium alginate (Na-alg) PEG-VS concentrations: (A) $0 \%(w / v) ;(\mathbf{B}) 1.25 \%(w / v) ;(\mathbf{C}) 5 \%(w / v)$ and (D) $10 \%(w / v)$. Upper row before liquefaction; lower row same batches after liquefaction with $200 \mathrm{mM}$ Na-citrate for 3 days. Scale bars: $500 \mu \mathrm{m}$.

A
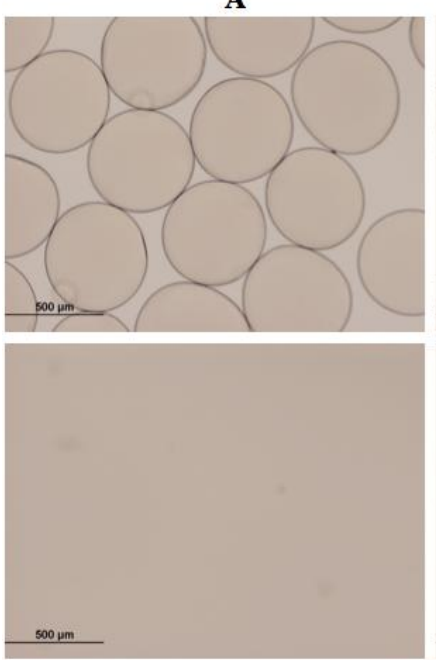

B
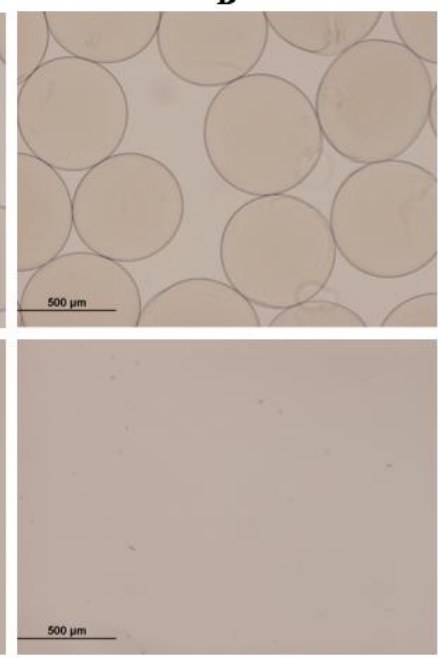
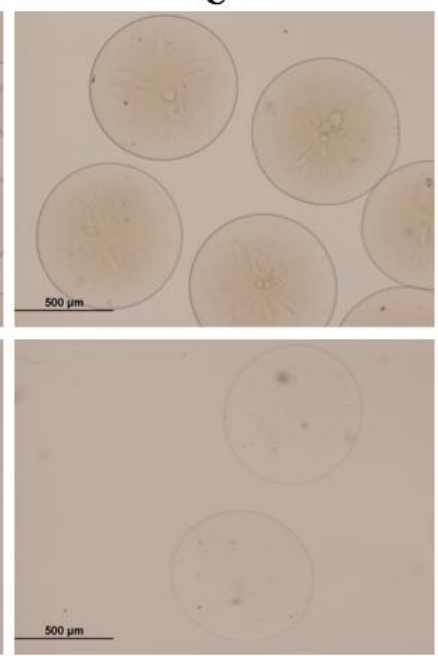

D
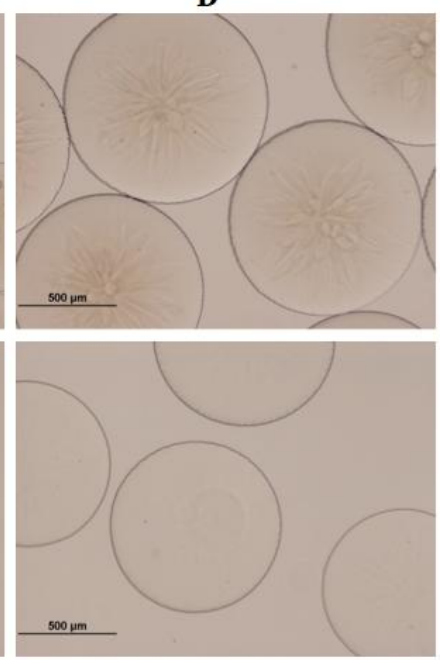

The mechanical resistance to compression clearly depends on the PEG-VS concentration, as shown in Figure 3. Figure 3A presents the resistance to coaxial compression up to $90 \%$ of the diameter of the microspheres, prepared with different PEG-VS concentrations. Considering the different size of the spheres in the four batches, Figure $3 \mathrm{~B}$ shows the volume corrected data to obtain a better comparison.

Figure 3. Mechanical resistance to compression up to $90 \%$ of the microsphere diameter of individual alg-PEG-M prepared with $0 \%-10 \%(w / v)$ PEG-VS $(n=30 \pm \mathrm{SD})$.
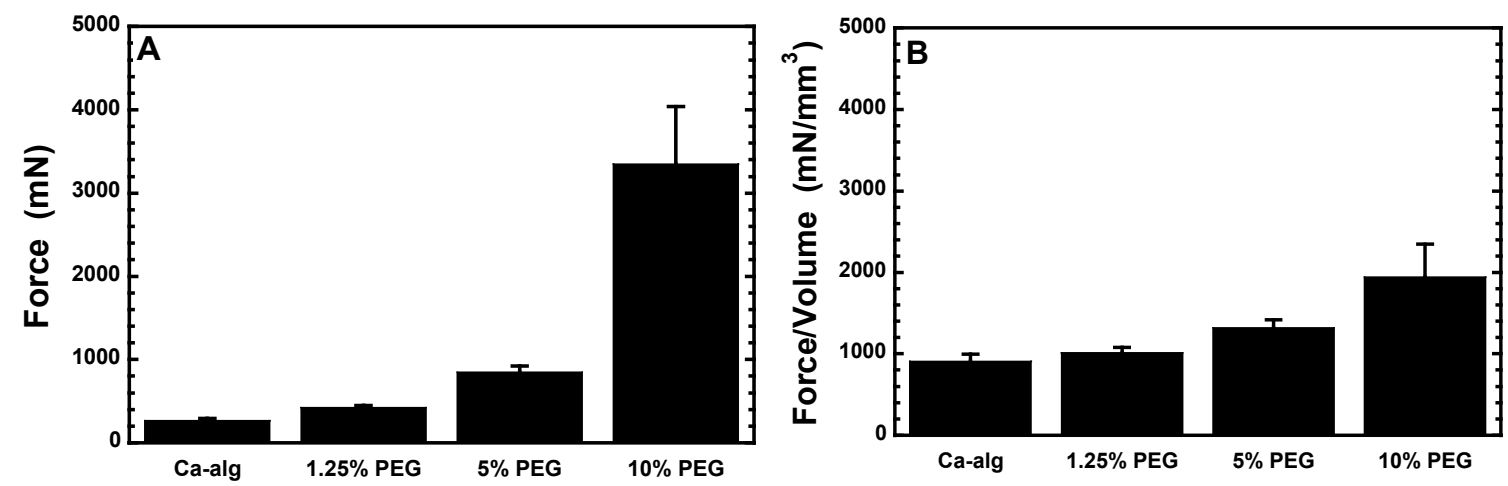


\subsection{Microencapsulation of Human Foreskin Fibroblasts}

EDX cells were successfully microencapsulated within alg-PEG-M prepared from PEG-8-20 at $10 \%(w / v)$ in DMEM containing 1.5\% (w/v) Na-alg. As shown in Figure 4, good sphericity was achieved for alg-PEG-M containing cells. The optical inspection of the gelation bath did not identify any free EDX cells. Thus, there was no out-diffusion of the cells from the polymer solution drops during the gelation process. This observation confirms that the total amount of EDX cells was embedded within alg-PEG-M. Moreover, the cells were almost homogenously distributed within the microsphere, and no empty microspheres were observed microscopically. Figure 4 shows a slight tendency of radial cell orientation, but no protruding cells were identified during the study.

Figure 4. Microphotographs of non-encapsulated (left panel) and microencapsulated primary human foreskin fibroblasts (EDX cells) (right panel), visualization of representative examples at different time points (in days) up to 20 days after microencapsulation. Top, light microscopy; bottom, viability staining of the same objects with fluorescein diacetate (green: living cells) and propidium iodide (red: dead cells). The average diameter of the microspheres was $550 \mu \mathrm{m}$. Scale bars: $100 \mu \mathrm{m}$.
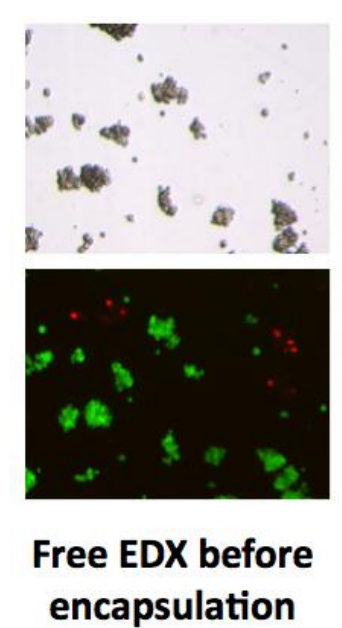

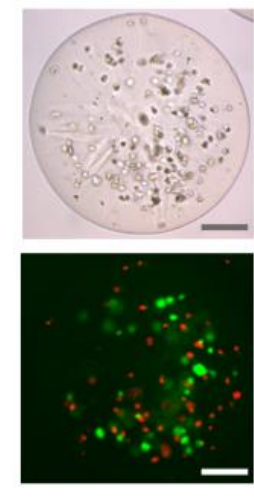

0

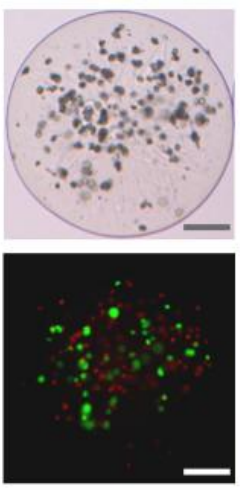

5

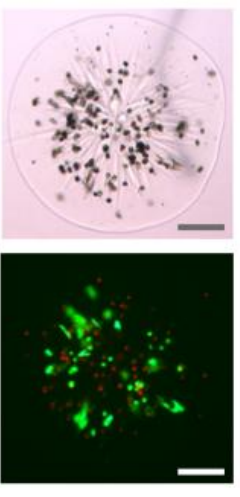

10

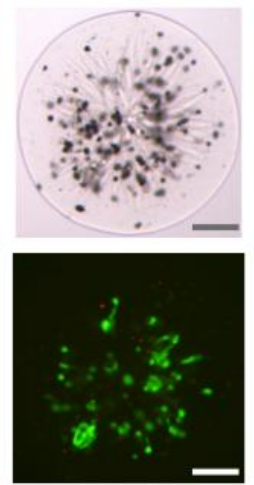

15

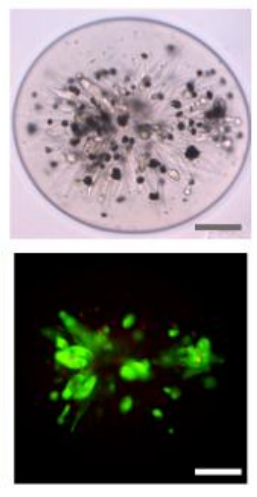

20

\section{Encapsulated EDX}

\subsection{Viability and Proliferation of Human Foreskin Fibroblasts}

The utilization of Dulbecco's Modified Eagle Medium (DMEM) as medium for cell microencapsulation was proven efficient in terms of providing a cell-friendly environment during the hydrogel formation. The cell viability, assessed qualitatively by staining with fluorescein diacetate and propidium iodide, revealed good survival immediately after the microencapsulation process. Viability of free EDX cells was $80.7 \% \pm 3.3 \%$ (mean \pm SD) following trypsinization, but $51.9 \% \pm 1.2 \%$ immediately after microencapsulation $(p=0.0002)$. However, microencapsulated EDX cells returned progressively to normal viability levels (i.e., $82.7 \% \pm 7.1 \%$ at day 20 ) when cultured in standard medium (IMDM supplemented with $10 \%$ fetal calf serum), i.e., similar values as observed for free EDX cells $(p=0.6575)$ (Figure 5).

The proliferation rate, after $24 \mathrm{~h}$ incubation with the thymidine analog EdU, was similar for free EDX cells $(6.2 \% \pm 2.2 \%)$ and microencapsulated EDX cells $(7.3 \% \pm 4.4 \%, p=0.6724)$ (Figure 6). 
Figure 5. Viability of microencapsulated EDX cells at various time points (days) up to 20 days after microencapsulation.

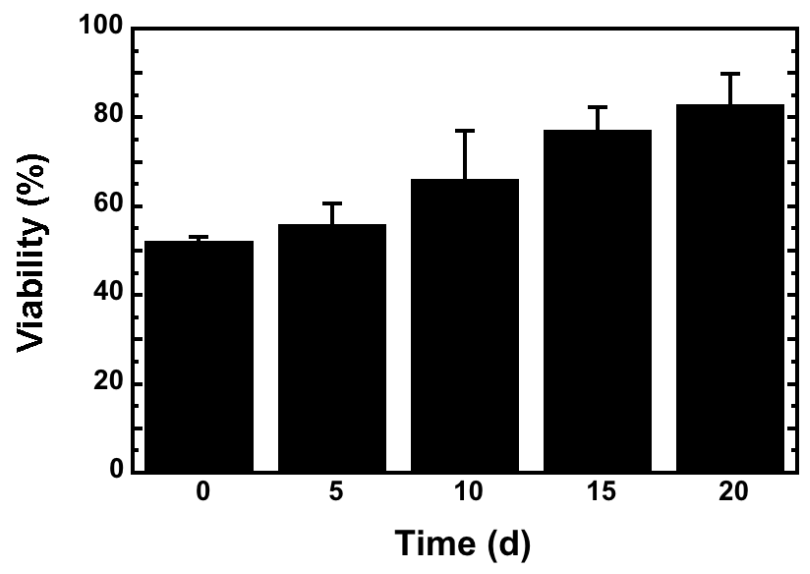

Figure 6. Proliferation of EDX cells $24 \mathrm{~h}$ after microencapsulation in alg-PEG-M. From left to right: green (EdU) shows proliferating cells; blue (Hoechst) shows all cells; Merge shows the overlay of EDU and Hoechst. Scale bars: $100 \mu \mathrm{m}$.

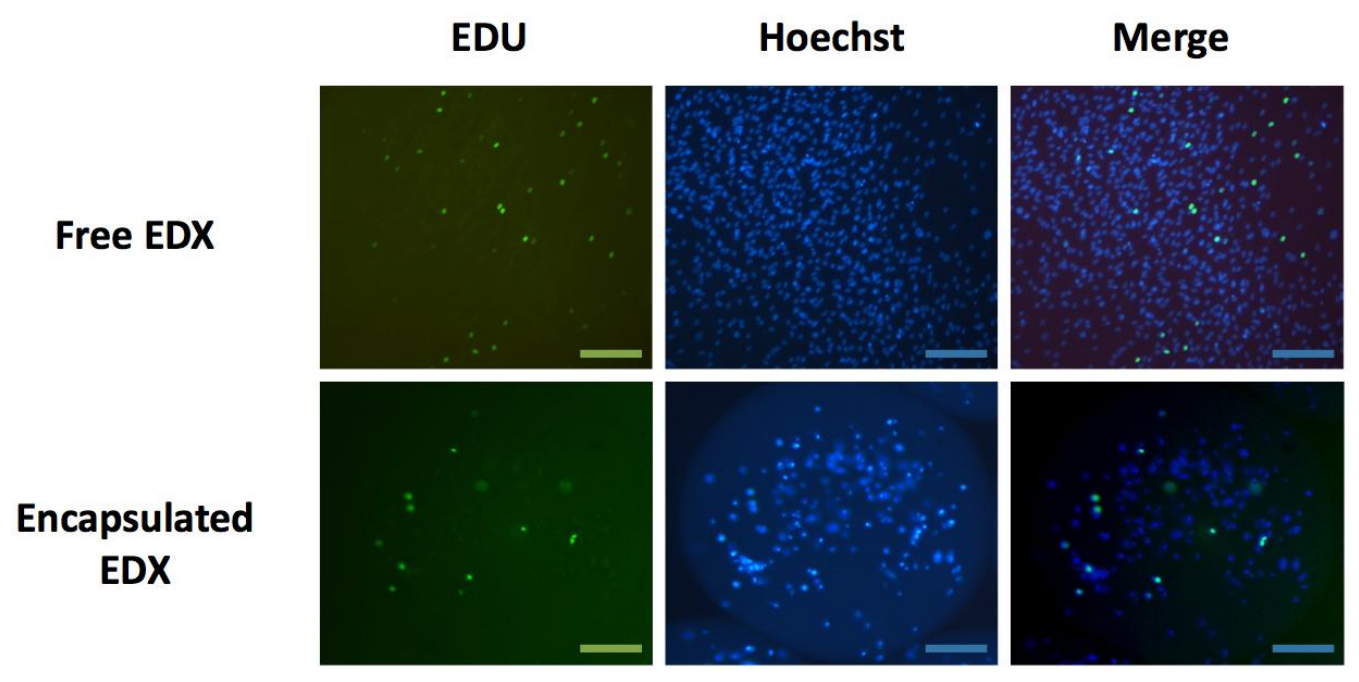

Human foreskin fibroblasts are primary cells of the mesenchymal lineage. They have been investigated in the field of regenerative medicine. Clinically, they have been used for the treatment of burns [32] and chronic venous ulcers [33,34]. In vitro experiments have shown that human foreskin fibroblasts have the potential to inhibit allogeneic mixed lymphocyte reactions and T-lymphocyte proliferation after mitogenic stimulation in vitro [35]. Human foreskin fibroblast cells are also often used as standard or control cells.

Using human foreskin fibroblasts allowed the demonstration that human primary cells tolerate the microencapsulation process with alg-PEG-M as hydrogel. The viability was slightly reduced immediately after the microencapsulation procedure, but returned to normal values within a few days. EDX cells recovered their normal "spindle-shaped" morphology after day 2, and kept their ability to proliferate within the microsphere at a normal rate when compared to non-encapsulated cells. The initially reduced viability upon microencapsulation can be attributed to mechanical stress applied to the cells during the extrusion through the needle. Optimized nozzle geometry could overcome this effect. 
Relying on basic studies related to the range of adaptability of the permeability and mechanical properties of the alg-PEG-M two-component hydrogel, the preparation with PEG-8-20 at 10\% $(w / v)$ was selected. As previously demonstrated, using the lower molar mass PEG-8-10 yields denser polymer networks, while the opposite effect was observed for the higher molar mass PEG-8-40 [31]. Less permeable hydrogels are also obtainable by increasing the PEG concentration to values up to $20 \%(w / v)$. However, there was a tendency that too compact hydrogels lead to inhomogeneous microsphere structures with a more compact core surrounded by a more permeable layer. The selection of 8 -arm PEG of the middle molar mass of $20 \mathrm{~kg} / \mathrm{mol}$ and preparation at $10 \%(w / v)$ in $1.5 \%(w / v)$ $\mathrm{Na}$-alg was confirmed as a suitable protocol for the microencapsulation of EDX cells. Inhomogeneity or phase separation were not observed, neither immediately after the preparation nor during storage in cell culture medium with serum supplements. Moreover, the microsphere size remained constant upon changing the culture medium during the experiment.

We conclude that this study is an encouraging step towards transplantation of allo- and xeno-geneic microencapsulated cells in order to treat congenital or acquired hormone/enzyme deficiencies as well as degenerative/inflammatory diseases.

\section{Experimental Section}

\subsection{Reagents}

Na-alg (PRONOVA UP LVM) was obtained from FMC BioPolymer (Novamatrix, Drammen, Norway, batch no FP-506-01). 8-arm PEG, molar mass $20 \mathrm{~kg} / \mathrm{mol}$, was purchased from JenKem (JenKem Technology USA Inc, Allen, TX, USA). This PEG consists of a poly(glycerol) backbone with multiple PEG arms attached through an ether bond (PEG-OH) (Scheme 1). Dulbecco's Modified Eagle Medium (DMEM, special formulation without $\mathrm{NaCl}$ and $\mathrm{KCl}$ ) was purchased from Cell Culture Technologies LLC (Gravessano, Switzerland). Divinylsulfone, DL-dithiothreitol (DTT), calcium chloride dihydrate, and sodium chloride were obtained from Sigma (Sigma-Aldrich, Buchs, Switzerland). All chemicals were of analytical grade and were used as supplied, unless otherwise indicated.

\subsection{Analytical Methods and Instrumentation}

Microphotographs were taken with an Olympus AX70 microscope connected to an Olympus DP70 color digital camera. The image analysis was performed using Olympus DP Manager software (Olympus, UK). The osmolality of the solutions was measured using a Micro-sample Osmometer (Fiske $^{\circledR}, 210$, Noorwood, MA, USA). Mechanical resistance measurements were performed at room temperature using a Texture Analyzer TA.XT.Plus (Stable Micro System LDT, Godalming, Surrey, UK) equipped with Texture Exponent 32 software (Stable Micro System LDT) for data analysis.

\subsection{Functionalization of Poly(ethylene glycol) with Vinyl Sulfone End Groups}

The vinyl sulfone-terminated derivative of PEG-OH (Scheme I) was synthesized as described previously [30]. The functionalized 8-arm PEG having the molar mass of $20 \mathrm{~kg} / \mathrm{mol}$ is designated as PEG-8-20. 


\subsection{Formation of Microspheres}

All components necessary for the preparation of microspheres were dissolved in a special DMEM preparation, which contained neither $\mathrm{NaCl}$ nor $\mathrm{KCl}$ in order to avoid too high osmolality upon dissolution of the polymers and salts. After dissolution of the reagents at their desired concentration, the osmolality was adjusted to that of basic DMEM without supplements $(\approx 300 \mathrm{mOsm} / \mathrm{kg}$ ) by adding $\mathrm{NaCl}$. The gelation bath was prepared by dissolving $\mathrm{CaCl}_{2}$ and DTT, in DMEM and adjusting the osmolality to $300 \mathrm{mOs} / \mathrm{kg}\left(80 \pm 5 \mathrm{mM} \mathrm{CaCl}_{2}\right)$. The microspheres were prepared under sterile conditions employing a coaxial airflow droplet generator [36].

As a typical example, $1.1 \mathrm{~g}$ of PEG-8-20 was dissolved in $10 \mathrm{~mL}$ of $1.65 \%(w / v) \mathrm{Na}$-alg aqueous stock solution yielding a solution, which had the final concentrations of $1.5 \%(\mathrm{w} / \mathrm{v}) \mathrm{Na}-\mathrm{alg}$ and $10 \%(w / v)$ PEG-VS. The solution was then sterile filtered $(0.2 \mu \mathrm{m})$, and $10 \mathrm{~mL}$ was extruded into $100 \mathrm{~mL}$ of the gelation bath containing $85 \mathrm{mM} \mathrm{Ca}^{2+}$ and $85 \mathrm{mg}$ DTT. The receiving bath was incubated in a shaker $(80 \mathrm{rpm})$ at $37{ }^{\circ} \mathrm{C}$ for up to $3 \mathrm{~h}$ to achieve optimal crosslinking [30]. Alg-PEG-M were collected by filtration.

For cell microencapsulation, the cells were added to the polymer solution before the extrusion into the gelation bath. After gelation and separation, the cell-containing microspheres were stored in the cell culture medium.

\subsection{Mechanical Testing}

Single microspheres were placed below the Texture Analyzer probe, which traveled toward the lower plane with a constant speed set at $0.5 \mathrm{~mm} / \mathrm{s}$. During probe displacement, the resistance of the sample to the compression was recorded up to a compression of $98 \%$ of the initial microsphere diameter. Thirty spheres of each batch were individually analyzed. The average mechanical resistance was then expressed as the mean \pm standard deviation (SD).

\subsection{Microencapsulation of Primary Human Foreskin Fibroblasts}

Primary human foreskin fibroblasts (in this study designated as EDX cells, a gift from DFB Bioscience) were detached using 0.25\% trypsin-EDTA (Sigma-Aldrich, Buchs, Switzerland) for about $30 \mathrm{~s}$ and washed twice. The EDX cell suspension was centrifuged at room temperature (1200 rpm, $5 \mathrm{~min})$ and the supernatant withdrawn. The pellet was resuspended in Na-alg/PEG-8-20 solution $(1.5 \%(w / v)$ Na-alg $+10 \%(w / v)$ PEG-8-20 in DMEM) to a final concentration of 500,000 cells $/ \mathrm{mL}$. The mixture was gently homogenized using a pipette and subsequently extruded into the sterile receiving bath, as described in Section 3.4. After filtration and washing, free and microencapsulated EDX cells were cultured in Iscove's modified Dulbecco's Medium (IMDM) (Cambrex, Verviers, Belgium) supplemented with $10 \%$ fetal calf serum (Gibco-Invitrogen, Basel, Switzerland), $100 \mathrm{IU} / \mathrm{mL}$ penicillin, and $100 \mathrm{mg} / \mathrm{mL}$ streptomycin (Gibco-Invitrogen). The medium was changed every three days.

\subsection{Viability and Proliferation Assays}

Fluorescein diacetate (FDA) living cell staining and propidium iodide (PI) dead cell staining (both from Sigma) were used to assess EDX cell viability. A mixture with FDA or PI was incubated 
for 2 min prior to evaluation. Cell viability was assessed immediately after microencapsulation (day 0) and at days 5, 10, 15, and 20. 5000 free and 1000 microencapsulated EDX cells were analyzed. The ratio between FDA-positive and PI-positive EDX cells was calculated using offline MetaMorph imaging software for microscopy (Universal Imaging, West Chester, PA, USA). To analyze proliferation, 5-ethynyl-2'-deoxyuridine (EdU), a nucleoside analog of thymidine that is incorporated into DNA during active DNA synthesis, was added to the culture medium immediately after microencapsulation. After $24 \mathrm{~h}$, free or encapsulated EDX cells were fixed with $4 \%$ paraformaldehyde for $15 \mathrm{~min}$ and permeabilized using $0.5 \%$ Triton X-100 for $5 \mathrm{~min}$. Proliferating cells were detected using the histochemical assay kit as described by the manufacturer (Click-iT ${ }^{\circledR}$ EdU Cell Proliferation Assays, Invitrogen Corp., Carlsbad, CA, USA). Hoechst 33342 (Sigma) was used to stain all EDX cell nuclei. A total of 4000 free and 1000 microencapsulated EDX cells were analyzed. Proliferation was expressed as percentage of proliferating cells (EdU-positive) with respect to the total number of cells (Hoechst-positive), using offline MetaMorph imaging software.

\subsection{Statistical Analysis}

The results were expressed as the mean \pm standard deviation. Unpaired Student's $t$-test was used to compare the mean values. A two-sided $p$ value $<0.05$ was considered significant. Computations were performed using GraphPad Prism, version 4.0 (GraphPad Software, Inc., La Jolla, CA, USA).

\section{Conclusions}

The development of novel materials and microencapsulation procedures contributes to accelerating the clinical implementation of cell microencapsulation. Moreover, from recent studies it can be concluded that the presence of polycations in the microspheres as well as multi-step encapsulation processes have disadvantages. Considering these aspects, novel hydrogel microspheres free of polycations and produced in one step in cell culture media have been developed and tested in the present study.

Alg-PEG-M microspheres were prepared by a process, which takes place in cell culture medium. Such a medium was used for both polymer solvent and solution with physiological osmolality to promote cell survival and integrity. The use of cell culture media neither negatively affected the preparation nor the physical properties of this type of hybrid microsphere. In addition, there are no positive charges present in the hydrogel, which could induce and promote protein and cell attachment.

Microencapsulation of primary cells, herein human foreskin fibroblasts, resulted in promising data regarding cell survival and function. The cell viability immediately after the microencapsulation procedure was slightly lower than for free cells. There was a similar proliferation rate observed for cells inside the microspheres and for free cells.

This first set of experiments confirmed the feasibility and physiological compatibility of cell microencapsulation within alg-PEG-M. This study is considered fundamental for future adaptation of alg-PEG-M to specific cell microencapsulation applications. 


\section{Acknowledgments}

This work was supported by the Swiss National Science foundation (Grants 205321-116397/1, 205320_130572/1, 205321_141286/1) and the Foundation InsuLeman, Geneva.

\section{Conflicts of Interest}

The authors declare no conflict of interest.

\section{References}

1. Bonavita, A.G.; Quaresma, K.; Cotta-de-Almeida, V.; Pinto, M.A.; Saraiva, R.M.; Alves, L.A. Hepatocyte xenotransplantation for treating liver disease. Xenotransplantation 2010, 17, 181-187.

2. Paul, A.; Ge, Y.; Prakash, S.; Shum-Tim, D. Microencapsulated stem cells for tissue repairing: Implications in cell-based myocardial therapy. Regener. Med. 2009, 4, 733-745.

3. De Vos, P.; Faas, M.M.; Strand, B.; Calafiore, R. Alginate-based microcapsules for immunoisolation of pancreatic islets. Biomaterials 2006, 27, 5603-5617.

4. Hernández, R.M.; Orive, G.; Murara, A.; Pedraz, J.L. Microcapsules and microcarriers for in situ cell delivery. Adv. Drug Deliv. Rev. 2010, 62, 711-730.

5. Rokstad, A.M.; Brekke, O.L.; Steinkjer, B.; Ryan, L.; Kolláriková, G.; Strand, B.L.; Skjåk-Braek, G.; Lacik, I.; Espevik, T.; Mollnes, T.E. Alginate microbeads are complement compatible, in contrast to polycation containing microcapsules, as revealed in a human whole blood model. Acta Biomater. 2011, 7, 2566-2578.

6. Rokstad, A.M.; Brekke, O.L.; Steinkjer, B.; Ryan, L.; Kolláriková, G.; Strand, B.L.; Skjåk-Braek, G.; Lambris, J.D.; Lacik, I.; Mollnes, T.E.; et al. The induction of cytokines by polycation containing microspheres by a complement dependent mechanism. Biomaterials 2013, 34, 621-630.

7. Moyer, H.R.; Kinney, R.C.; Singh, K.A.; Williams, J.K.; Schwartz, Z.; Boyan, B.D. Alginate microencapsulation technology for the percutaneous delivery of adipose-derived stem cells. Ann. Plast. Surg. 2010, 65, 497-503.

8. Malpique, R.; Osorio, L.M.; Ferreira, D.S.; Ehrhart, F.; Brito, C.; Zimmermann, H.; Alves, P.M.; Alginate encapsulation as a novel strategy for the cryopreservation of neurospheres. Tissue Eng. Methods 2010, 16, 965-977.

9. Park, H.S.; Ham, D.S.; You, Y.H.; Shin, J.; Kim, J.W; Jo, J.H; Kim, O.Y.; Khang, G.; Yoon, K.H. Successful xenogenic islet transplantation with $\mathrm{Ba}^{2+}$-Alginate encapsulation. Tissue Eng. Regen. Med. 2010, 7, 523-530.

10. Penolazzi, L.; Tavanti, E.; Vecchiatini, R.; Lambertini, E.; Vesce, F.; Gambari, R.; Mazzitelli, S.; Mancuso, F.; Luca, G.; Nastruzzi, C.; et al. Encapsulation of mesenchymal stem cells from Wharton's Jelly in alginate microbeads. Tissue Eng. Methods 2010, 16, 141-155.

11. Endres, M.; Wenda, N.; Woehlecke, H.; Neumann, K.; Ringe, J.; Erggelet, C.; Lerche, D.; Kaps, C. Microencapsulation and chondrogenic differentiation of human mesenchymal progenitor cells from subchondral bone marrow in Ca-alginate for cell injection. Acta Biomater. 2010, 6, 436-444. 
12. Cui, H.; Tucker-Burden, C.; Cauffield, S.M.D.; Barry, A.K.; Iwakoshi, N.N.; Weber, C.J.; Safley, S.A. Long-term metabolic control of autoimmune diabetes in spontaneously diabetic nonobese diabetic mice by nonvascularized microencapsulated adult porcine islets. Transplantation 2009, 88, 160-169.

13. Dang, T.T.; Thai, A.V.; Cohen, J.; Slosberg, J.E.; Siniakowicz, K.; Doloff, J.C.; Ma, M.; Hollister-Lock, J.; Tang, K.M.; Gu, Z.; et al. Enhanced function of immuno-isolated islets in diabetes therapy by co-encapsulation with an anti-inflammatory drug. Biomaterials 2013, 34, 5792-5801.

14. Giovagnoli, S.; Blasi, P.; Luca, G.; Fallarino, F.; Calvitti, M.; Mancuso, F.; Ricci, M.; Basta, G.; Becchetti, E.; Rossi, C.; et al. Bioactive long-term release from biodegradable microspheres preserves implanted ALG-PLO-ALG microcapsules from in vivo response to purified alginate. Pharm. Res. 2010, 27, 285-295.

15. De Castro, M.; Orive, G.; Hernández, R.M.; Bartkowiak, A.; Brylak, W.; Pedraz, J.L. Biocompatibility and in vivo evaluation of oligochitosans as cationic modifiers of alginate/Ca microcapsules. J. Biomed. Mater. Res. 2009, 91, 1119-1130.

16. Babister, C.; Tare, R.S.; Green, D.W.; Inglis, S.; Mann, S. Genetic manipulation of humanmesenchymal progenitors to promote chondrogenesis using "bead-in-bead" polysaccharide capsules. Biomaterials 2008, 29, 58-65.

17. Baruch, L.; Machluf, M. Alginate-chitosan complex coacervation for cell encapsulation: Effect on mechanical properties and on long-term viability. Biopolymers 2006, 82, 570-579.

18. Yu, C.B.; Lv, G.L.; Pan, X.P.; Chen, Y.S.; Cao, H.C.; Zhang, Y.M.; Du, W.B.; Yang, S.G.; $\mathrm{Li}$, L.J. In vitro large-scale cultivation and evaluation of microencapsulated immortalized human hepatocytes (HepLL) in roller bottles. Int. J. Artif. Organs 2009, 32, 272-281.

19. Luna, S.M.; Gomes, M.E.; Mano, J.F.; Reis, R.L. Development of a novel cell encapsulation system based on natural origin polymers for tissue engineering applications. J. Bioact. Compat. Pol. 2010, 25, 341-359.

20. Mazumder, M.A.J.; Burke, N.A.D.; Shen, F.; Potter, M.A.; Stöver, H.D.H. Core crosslinked alginate microcapsules for cell encapsulation. Biomacromolecules 2009, 10, 1365-1373.

21. Gardner, C.M.; Burke, N.A.D; Stöver, H.D.H. Cross-linked microcapsules formed from self-deactivating reactive polyelectrolytes. Langmuir 2010, 26, 4916-4924.

22. Gardner, C.M.; Potter, M.A.; Stöver, H.D.H. Improving covalent cell encapsulation with temporarily reactive polyelectrolytes. J. Mater. Sci. Mater. Med. 2012, 23, 181-193.

23. Rokstad, A.M.; Brekke, O.L.; Steinkjer, B.; Ryan, L.; Kolláriková, G.; Lambris, J.D.; Lacik, I.; Mollnes, T.E.; Espevik, T. Poly-cation containing alginate microcapsules induce cytokines by a complement-dependent mechanism. Immunobiology 2012, 217, 1221-1221.

24. Luan, N.M.; Teramura, Y.; Iwata, H. Immobilization of the soluble domain of human complement receptor 1 on agarose-encapsulated islets for the prevention of complement activation. Biomaterials 2010, 31, 8847-8853.

25. Stiegler, P.; Matzi, V.; Pierer, E.; Hauser, O.; Schaffellner, S.; Renner, H.; Greilberger, J.; Aigner, R.; Maier, A.; Lackner, C.; et al. Creation of a prevascularized site for cell transplantation in rats. Xenotransplantation 2010, 17, 379-390. 
26. Wells, L.A.; Sheardown, H. Photosensitive controlled release with polyethylene glycol-anthracene modified alginate. Eur. J. Pharm. Biopharm. 2011, 79, 304-313.

27. Davidovich-Pinhas, M.; Bianco-Peled, H. Physical and structural characteristics of acrylatedpoly(ethylene glycol)-alginate conjugates. Acta Biomater. 2011, 7, 2817-2825.

28. Yang, J.S.; Xie, Y.J.; He, W. Research progress on chemical modification of alginate: A review. Carbohydr. Polym. 2011, 84, 33-39.

29. Hall, K.K.; Gattás-Asfura, K.M.; Stabler, C.L. Microencapsulation of islets within alginate/poly(ethylene glycol) gels cross-linked via Staudinger ligation. Acta Biomater. 2011, 7 , 614-624.

30. Mahou, R.; Wandrey, C. Alginate-poly(ethylene glycol) hybrid microspheres with adjustable physical properties. Macromolecules 2010, 43, 1371-1378.

31. Mahou, R.; Kolláriková, G.; Gonelle-Gispert, C.; Meier, R.; Schmitt, F.; Tran, N.M.; Dufresne, M.; Lacik, I.; Bühler, L.; Juillerat-Jeanneret, L.; et al. Combined electrostatic and covalent polymer networks for cell microencapsulation. Macromol. Symp. 2013, 329, 49-57.

32. Nanchahal, J.; Dover, R.; Otto, W.R. Allogeneic skin substitutes applied to burns patients. Burns 2002, 28, 254-257.

33. Falanga, V.; Margolis, D.; Alvarez, O.; Auletta, M.; Maggiacomo, F.; Altman, M.; Jensen, J.; Sabolinski, M.; Hardin-Young, J. Rapid healing of venous ulcers and lack of clinical rejection with an allogeneic cultured human skin equivalent. Arch. Dermatol. 1998, 34, 293-300.

34. Yonezawa, M.; Tanizaki, H.; Inoguchi, N.; Ishida, M.; Katoh, M.; Tachibana, T.; Miyachi, Y.; Kubo, K.; Kuroyanagi, Y. Clinical study with allogeneic cultured dermal substitutes for chronic leg ulcers. Int. J. Dermatol. 2007, 46, 36-42.

35. Wada, N.; Bartold, P.M.; Gronthos, S. Human foreskin fibroblasts exert immunomodulatory properties by a different mechanism to bone marrow mesenchymal stem cells. Stem Cells Dev. 2011, 20, 647-659.

36. Ceausoglu, I.; Hunkeler, D. A new microencapsulation device for controlled membrane and capsule size distributions. J. Microencapsul. 2002, 19, 725-735.

(C) 2014 by the authors; licensee MDPI, Basel, Switzerland. This article is an open access article distributed under the terms and conditions of the Creative Commons Attribution license (http://creativecommons.org/licenses/by/3.0/). 